\title{
French Recommendations for Osteoporosis Prevention and Treatment in Patients with Prostate Cancer Treated by Androgen Deprivation
}

Karine Briot ${ }^{\mathrm{a} *}$, Julien Paccou ${ }^{\mathrm{b} *}$, Philippe Beuzeboc ${ }^{\mathrm{c}}$, Jacques Bonneterre ${ }^{\mathrm{d}}$, Béatrice Bouvard $^{\mathrm{e}}$, Cyrille B Confavreux ${ }^{\mathrm{f}}$, Catherine Cormier $^{\mathrm{a}}$, Bernard Cortet $^{\mathrm{b}}$, Jean-Michel Hannoun-Lévi ${ }^{\mathrm{g}}$, Christophe Hennequin ${ }^{\mathrm{h}}$, Rose-Marie Javier ${ }^{\mathrm{i}}$, Eric Lespessailles ${ }^{\mathrm{j}}$, Didier Mayeur $^{\mathrm{k}}$, Pierre Mongiat Artus ${ }^{1}$, Marie-Hélène Vieillard ${ }^{\mathrm{b}, \mathrm{m}}$, Françoise Debiais ${ }^{\mathrm{n}}$

*These two authors contributed equally to this work.

${ }^{a}$ Service de rhumatologie, Hôpital Cochin 74014 Paris, France

${ }^{\mathrm{b}}$ Service de rhumatologie, CHU de Lille, 59037 Lille, France

${ }^{c}$ Département d'oncologie médicale, Institut Curie, 75005 Paris, France

${ }^{\mathrm{d}}$ Département de cancérologie sénologique, Centre Oscar Lambret, 59000 Lille, France

${ }^{\mathrm{e}}$ Service de rhumatologie, CHU d'Angers, 49100 Angers, France

${ }^{\mathrm{f}}$ Service de rhumatologie, Hospices Civils de Lyon, 69003 Lyon ; INSERM UMR 1003 -

Lyos, Université de Lyon, 69000 Lyon, France

${ }^{\mathrm{g}}$ Service de radiothérapie, Centre Antoine Lacassagne, 06100 Nice, France

${ }^{\mathrm{h}}$ Service de cancérologie et radiothérapie, Hôpital Saint Louis, 75010 Paris, France

${ }^{\text {i }}$ Service de rhumatologie, CHU de Strasbourg, 67000 Strasbourg, France

${ }^{\mathrm{j}}$ Service de rhumatologie, CHR d'Orléans, 45067 Orléans, France

${ }^{\mathrm{k}}$ Service d'oncologie, Centre hospitalier de Versailles, 78150 Le Chesnay, France

${ }^{1}$ Service d'urologie, Hôpital Saint Louis, 75010 Paris, France

${ }^{\mathrm{m}}$ Service d'oncologie, Centre Oscar Lambret, 59000 Lille, France

${ }^{\mathrm{n}}$ Service de rhumatologie, CHU de Poitiers ; 86021 Poitiers, France 
Corresponding author: Françoise Debiais, Service de rhumatologie, CHU de Poitiers, 2 rue de la Milétrie 86021 Poitiers, FRANCE

Tel.: +33 549444465

E-mail: f.debiais@chu-poitiers.fr 


\section{ABSTRACT}

Androgen-deprivation therapy (ADT) in patients with prostate cancer can be achieved surgically or chemically, notably by prescribing LHRH analogs. Major bone loss occurs rapidly in both cases, due to the decrease in testosterone levels, and can increase the fracture risk. The objective of developing these recommendations was to achieve a practical consensus among various scientific societies, based on a literature review, about osteoporosis prevention and treatment in patients on ADT. The following scientific societies contributed to the work: Société Française de Rhumatologie (SFR), Groupe de Recherche et d'Information sur les Ostéoporoses (GRIO), Groupe Européen d'Etudes des Métastases Osseuses (GEMO), Association Francophone pour les SOins de Support (AFSOS), Association Française d'Urologie (AFU), Société Française de Radiothérapie Oncologique (SFRO). Medication prescription and reimbursement modalities in France were taken into account. The recommendations state that a fracture-risk evaluation and interventions targeting risk factors for fractures should be provided to all patients on ADT. Those patients with a history of severe osteoporotic fracture and/or a T-score $<-2.5$ should receive osteoporosis therapy. Patients whose T-score is between -1.5 and -2.5 should be treated if they exhibit at least two other risk factors among the following: age $\geq 75$ years, history of nonsevere fracture after 50 years of age, body mass index $<19 \mathrm{~kg} / \mathrm{m}^{2}$, at least three comorbidities (e.g., cardiovascular disease, depression, Parkinson's disease, and dementia), current glucocorticoid therapy, and repeated falls. When the decision is difficult, FRAX ${ }^{\circledR}$ score determination and an assessment by a bone disease specialist may be helpful. When osteoporosis therapy is not indicated, general measures should be applied, and bone mineral density measured again after 12-24 months. The anti-tumor effects of bisphosphonates and denosumab fall outside the scope of these recommendations. 
Keywords: Prostate cancer. Bone loss. Fracture. Osteoporosis. LHRH agonists. Surgical orchiectomy. Androgen deprivation therapy. Prevention. Bisphosphonates. Denosumab. Recommendations. 


\section{Introduction}

Data collected in 2015 indicate that prostate cancer is by far the most common malignancy in males in continental France, with 53913 new diagnoses per year, compared to 30401 for lung cancer and 23535 for colorectal cancer. The number of deaths due to cancer in males in continental France in 2015 was estimated at 84 041, with lung cancer being the leading cause (20 990 deaths), followed by colorectal cancer (9337 deaths) then by prostate cancer (8713 deaths) [1].

The treatment of localized prostate cancer depends on the risk of recurrence as determined based on the D'Amico risk classification [2,3] (Table 1). The main treatment tools are radical prostatectomy, radiotherapy, and pharmacological androgen-deprivation therapy (PADT, also known as chemical castration). PADT is used chiefly in patients who are at intermediate and high risk according to the D'Amico risk classification, have metastases, or experience a biochemical recurrence.

PADT is more widely used than surgical orchiectomy and usually consists in administering an analog of luteinizing hormone-releasing hormone (LHRH), which binds to the pituitary LHRH receptors, thereby diminishing the production of LH and FSH and causing a drop in testosterone levels. A peripheral antiandrogen is given concomitantly for about 1 month to avoid initial transient stimulation of the pituitary with a flare-up of testosterone levels. In some situations, such as a risk of spinal cord compression, LHRH antagonists that directly block the pituitary LHRH receptors are given, as they cause no flare-up effect. Finally, peripheral antiandrogens can be used for PADT (Table 2). 
The duration of PADT in patients with localized prostate cancer varies according to the level of risk, from about 6 months if the risk is intermediate $[4,5]$ to $18-36$ months if the risk is high $[6,7]$. In patients with metastatic disease, PADT can be given intermittently or continuously $[8,9,10]$. In the event of PADT resistance, continuous LHRH therapy is combined with second-generation hormone therapy (e.g., abiraterone [10] or enzalutamide [11]) or with cancer chemotherapy (e.g., docetaxel [12] or cabazitaxel [13]). Metabolic radiotherapy can also be used in patients with metastatic prostate cancer. In recent studies, radium-223 dichloride $\left(\right.$ Xofigo $^{\circledR}$, formerly Alpharadin ${ }^{\circledR}$ ) increased the overall survival of patients with bone metastases from prostate cancer [14].

The most common adverse effects of PADT can be categorized as clinical (hot flashes, mastodynia, decreased size of the external genitalia, decreased libido, weight gain) and metabolic (insulin resistance, metabolic syndrome, dyslipidemia), increased risk of coronary artery disease, loss of muscle mass, and decreased hemoglobin levels) [15]. In addition, the decrease in testosterone levels induced by surgical or chemical castration causes major and rapid bone loss that predominantly affects the trabecular bone. Consequently, the fracture risk may increase, depending on patient age. Peripheral antiandrogens have no effects on bone, as they do not decrease the testosterone levels when used alone [15].

\section{Objectives and methodology}

These recommendations are intended for all physicians involved in the prevention and treatment of bone loss caused by ADT in patients with localized prostate cancer. The management of patients with bone metastases is outside the scope of these recommendations. 
These recommendations discuss the principles underlying the pharmacological treatment of ADT-related bone loss, based on the efficacy and safety of each drug, as well as on current indications and reimbursement policies in France. Treatment strategies appropriate for various clinical situations are described.

The content of these recommendations was discussed, drafted, and validated according to the method developed by the French National Authority for Health (Haute Autorité de Santé, HAS). Thus, the recommendations were drafted by a project manager and scientific committee then discussed and revised by a multidisciplinary panel. When published data were inadequate or incomplete, recommendations were developed by professional consensus based on current practice and expert opinion, after an analysis of recent European and American recommendations $[16,17]$. The recommendations presented here cannot consider all specific situations, comorbidities, hospital-care protocols, etc. They do not claim to cover all possible management strategies and cannot serve as a substitute for each physician's individual responsibility toward each patient.

The following scientific societies contributed to develop and revise these recommendations: Association Francophone pour les SOins de Support (AFSOS), Association Française d'Urologie (AFU), Groupe Européen d'Etudes des Métastases Osseuses (GEMO), Groupe de Recherche et d'Information sur les Ostéoporoses (GRIO), Société Française de Radiothérapie Oncologique (SFRO), Société Française de Rhumatologie (SFR).

\section{Bone effects of androgen-deprivation therapy for prostate}

\section{cancer}




\subsection{Risk of osteoporosis and bone loss}

Most of the data on bone effects of ADT come from studies of patients managed with surgical orchiectomy or LHRH agonist therapy. The prevalence of osteoporosis in patients given LHRH analogs to treat prostate cancer varied between $10 \%$ and $40 \%$ depending on the characteristics of the study population and increased with age and treatment duration $[18,19$, 20], reaching $80 \%$ after 10 years of drug exposure [19].

The annual rate of bone loss in males is usually $0.5 \%$ to $1 \%$ and increases in the event of LHRH agonist therapy or surgical orchiectomy. Bone loss during LHRH therapy is significant at all measurement sites and is marked even during the first year of treatment. Thus, bone loss after 1 year ranged from $2.1 \%$ to $4.6 \%$ at the lumbar spine $[20,21,22,23]$ and from $1.9 \%$ to $3.9 \%$ at the hip $[22,24,25,26]$. After surgical orchiectomy, bone mineral density (BMD) at the femoral neck diminished by $2.4 \%$ after 1 year and $10 \%$ after 2 years [24]. Bone loss is associated with the risk of incident fractures [27].

Few studies have assessed BMD changes after treatment discontinuation in this population. After the treatment is stopped, BMD may increase at the lumbar spine, while remaining below the baseline value $[22,28,29]$. In contrast, no increase is observed at the hip.

Risk factors for bone loss are older age and lower body mass index (BMI) [20, 24, 30]. Bone loss is associated with body composition changes combining a loss of muscle mass (sarcopenia) with an increase in fat mass [18].

\subsection{Fracture risk}

In studies of databases, registries, and patient cohorts, LHRH analog therapy was associated with an increased risk of both vertebral and nonvertebral fractures, notably at the 
proximal femur, in males older than 50 years [27, 31, 32, 33]. In a comparative study, the risk of experiencing a fracture between 1 and 5 years after the diagnosis of prostate cancer was $19.4 \%$ with versus $12.6 \%$ without LHRH analog therapy $(p<0.001)$ [32]. In another study, the relative risk (RR) of fracture in patients given LHRH analog therapy was 1.21 (95\% confidence interval $[95 \% \mathrm{CI}], 1.14-1.29 ; p<0.001)$ for fractures at any site, $1.45(95 \% \mathrm{CI}$, $1.19-1.75 ; p<0.001)$ for vertebral fractures, and $1.30(95 \%$ CI $1.10-1.53 ; p=0.002)$ for hip fractures [31]. This increase in the fracture risk is associated with an increase in mortality that is greater than that seen with similar risk increases in women [34]. In addition to hip fractures, other osteoporotic fractures classified as severe are associated with increased mortality, including fractures of the proximal humerus, vertebras, pelvis, distal femur, three or more consecutive ribs, and proximal tibia [35].

Osteoporotic vertebral fractures are often underestimated. In a study involving a routine vertebral fracture assessment (VFA) in patients given LHRH analogs for longer than 6 months to treat prostate cancer, the prevalence of vertebral fractures was $37 \%$, and nearly $95 \%$ of vertebral fractures were not previously known to the patients [36]. These results are similar to those produced by studies of patients with glucocorticoid-induced osteoporosis [37]. Although not all vertebral fractures are due to osteoporosis, in patients with prostate cancer a diagnosis of vertebral fracture does not necessarily indicate a metastasis and requires appropriate etiological investigations.

The fracture risk increases with the number of LHRH analog injections after the first 6 treatment months [32]. The main risk factors for fracture in patients on LHRH analog therapy are older age, a history of fracture, osteoporosis, and the rate of bone loss during treatment [27, $38,39]$. The role for age was shown in a study in which patients aged 75 to 84 years and those aged 85 years or older had a higher risk of fragility fractures than did patients aged 65 to 74 
years (75-84 years: hazard ratio [HR], 1.79; 95\%CI, 1.65-1.94; and $\geq 85$ years: $\mathrm{HR}, 3.23$; 95\%CI, 2.85-3.66) [38].

Prostate cancer per se is not an independent risk factor for fractures [40].

\subsection{Fall risk}

Over $80 \%$ of nonvertebral fractures occur during a fall [41]. Few studies have evaluated the incidence and prevalence of falls in patients with prostate cancer. In a case-control study of males aged 60 years or older who were treated for prostate cancer, the risk of incident falls was significantly higher in the subgroup on LHRH analog therapy for biochemical recurrence $(n=63)$ than in the control group of patients without LHRH analog therapy or biochemical recurrence $(\mathrm{n}=71)(14.3 \%$ vs. $2.8 \%, p=0.02)$. By multivariate analysis, comorbidities were significantly associated with the fall risk (OR, 2.02, $p=0.01)$, whereas LHRH analog therapy was not $(\mathrm{OR}, 4.74, p=0.11)$ [42]. The risk of falls is increased by the muscle mass loss related to the drop in testosterone levels induced by ADT.

\section{Evaluating the fracture risk in patients receiving androgen- deprivation therapy (ADT)}

Several studies, most of which were done in patients receiving LHRH agonists, demonstrated rapid increases in the rate of bone loss and risk of fractures after the initiation of ADT. Therefore, the fracture risk should be evaluated in all patients at treatment initiation. If no baseline evaluation was performed and the patient has already received ADT, the fracture risk should be evaluated immediately ( $\underline{\text { Grade A)}}$. 
The identification of patients at high risk for fractures relies on a multifactorial evaluation. Thus, the characteristics of the patient should be evaluated, as well as a history of low-energy fractures after 50 years of age, the risk factors for osteoporosis and falls, and BMD values.

\subsection{History of fractures}

Patients should be asked whether they have sustained one or more low-energy fractures (e.g., due to a fall from standing height) after 50 years of age, as this is the main risk factor for further fractures [27, 38, 39] (Grade A).

The prevalence of vertebral fractures is increased, and many vertebral fractures cause little or no symptoms [36]. Radiographs of the spine should not be obtained routinely, however. The indications are back pain or loss of height $\geq 4 \mathrm{~cm}$ versus height at 20 years of age or $\geq 2 \mathrm{~cm}$ during follow-up (Professional consensus). Vertebral fractures can be detected by using a dual-energy X-ray absorptiometry machine to perform a VFA. As the radiation dose is very low, a VFA can be performed at baseline or during ADT at the same time as BMD measurements [43]. VFA is not currently reimbursed by the French statutory health insurance system.

\subsection{Evaluation of risk factors}

\subsubsection{Evaluation of risk factors for osteoporotic fractures}

The main risk factors for osteoporotic fractures in males given ADT (usually with LHRH analogs) are age $\geq 75$ years, history of low-energy fracture after 50 years of age, osteoporosis defined as a T-score $\leq-2.5$ at one or both measurement sites, BMI $<19 \mathrm{~kg} / \mathrm{m}^{2}$, at 
least three comorbidities (e.g., cardiovascular disease, depression, Parkinson's disease, dementia), and current or past glucocorticoid therapy.

\subsubsection{Evaluation of risk factors for fall}

Risk factors for falls make a major contribution to the occurrence of fractures in the oldest patients. In 2005, the HAS recommended routinely identifying patients at high risk for falls (http//www.hassante.fr/portail/upload/docs/application/pdf/prevention_des_chutesargumentaire.pdf) by asking about a history of one or several falls during the past year and, in the absence of falls, by looking for risk factors for falls or performing one of the following simple tests during the physician visit: get-up-and-go, single-leg stance, and sternal nudge.

The G8 questionnaire ( http://www.siog.org/files/public/g8_english_0.pdf and www.ecancer.fr/oncodage) is geriatric screening tool used in cancer patients older than 70 years to determine whether a full geriatric assessment is in order [44]. A score lower than 14 indicates that a full geriatric assessment should be performed.

\subsection{Bone mineral density (DMO) measurement}

BMD should be measured routinely in patients scheduled for ADT and, if no baseline assessment was performed, in patients receiving ADT (Grade A). BMD measurement is reimbursed in France for patients who have a prescription for ADT.

In practice, despite the absence of a consensus, the World Health Organization (WHO) definition of osteoporosis (T-score $\leq-2.5$ at one or more measurement sites) can be applied in males provided the reference population is a cohort of young males [45, 46, 47, 48]. BMD should be measured at the hip (femoral neck and total hip) and lumbar spine. The values at the spine may be artefactually increased in patients with degenerative disease, which is common in older individuals. 


\subsection{The FRAX ${ }^{\circledR}$ score}

Hypogonadism is a cause of secondary osteoporosis and is a risk factor included in the FRAX $^{\circledR}$ score developed by the WHO to quantify the 10 -year absolute fracture risk in patients older than 40 years (www.sheffield.ac.uk/FRAX) [49]. An analysis of 12 international cohorts including a total of about 60000 individuals was performed to identify risk factors and to determine their performance in predicting fractures. The following risk factors were selected for the $\mathrm{FRAX}^{\circledR}$ score: age, BMI, history of fracture, history of hip fracture in one or both parents, current smoking, glucocorticoid therapy, rheumatoid arthritis (RA), other causes of secondary osteoporosis, alcohol abuse, and BMD at the femoral neck. The FRAX ${ }^{\circledR}$ score estimates the 10-year risk of hip fracture and of major fractures defined as fractures of the hip, humerus, and wrist and as symptomatic vertebral fractures.

However, the FRAX $^{\circledR}$ score has many limitations. In addition, no validated cutoff for initiating osteoporosis therapy has been defined for males in France, and no studies of the FRAX $^{\circledR}$ score have been conducted in patients with prostate cancer. Consequently, determining the $\mathrm{FRAX}^{\circledR}$ score is not recommended as a first-line measure for identifying patients at risk of osteoporotic fractures among men receiving ADT. Nevertheless, when the appropriateness of osteoporosis therapy is difficult to assess, notably in patients who have no history of severe fractures or do not meet the BMD criterion for osteoporosis, it may be helpful to determine the FRAX ${ }^{\circledR}$ score and, if needed, to obtain advice from a bone disease specialist.

Use of the FRAX ${ }^{\circledR}$ score for deciding whether to start osteoporosis treatment in patients taking ADT for prostate cancer has been recommended. The score cutoffs above which treatment is given are $20 \%$ for major fractures (femur, wrist, humerus, vertebras) and $3 \%$ for hip fractures (Professional consensus) $[16,17]$. 


\subsection{Assays of bone turnover markers}

No data are available on the usefulness of assaying markers of bone turnover (bone resorption and bone formation) in patients with osteoporosis induced by ADT.

Consequently, bone turnover marker assays are not recommended for predicting the fracture risk.

\section{Treatment prerequisites}

The measures listed below are indispensable (Professional consensus):

- The patient should be evaluated for other known risk factors for osteoporosis, most notably those amenable to modification, including smoking, alcohol abuse, vitamin D deficiency, and inadequate dietary calcium intake.

- Other causes of bone fragility should be ruled out, in particular by standard blood tests including at least a full blood cell count and platelet count; erythrocyte sedimentation rate or C-reactive protein level; serum levels of calcium, phosphate, creatinine, total alkaline phosphatase, and 25-OH vitamin D; and serum protein electrophoresis (Professional consensus).

- In elderly individuals, measures effective in decreasing the risk of falls and fractures include hazard-proofing the home, physical activity programs, correcting visual disorders, and adjusting antihypertensive or hypnotic medications. These measures should be applied (Grade A). The muscle mass loss induced by LHRH agonists increases the importance of fall prevention [18].

\subsection{Calcium intake}


In France, the National Nutrition-for-Health Program (Programme National Nutrition Santé, PNNS) recommends a daily calcium intake of 800-1200 mg, i.e., four servings of dairy products such as yogurt, cottage cheese, fermented milk, cheese, and milk. Dietary sources of calcium have the added advantage of supplying the proteins needed to maintain bone health. In practice, the daily dietary calcium intake can be estimated using the online food-frequency questionnaire available at www.grio.org. Routine calcium supplementation is not recommended before an evaluation of the dietary calcium intake (Grade A).

\subsection{Vitamin D supply}

Given the risk of bone loss associated with ADT, the serum level of 25(OH)D should be assayed ( $\underline{\text { Grade A)}}$. The optimal serum level of $25(\mathrm{OH}) \mathrm{D}$ should be achieved. This optimal level has been determined to be $30 \mathrm{ng} / \mathrm{mL}$ ( $75 \mathrm{nmol} / \mathrm{L}$ ) [50] based on clinical and laboratory data obtained in studies that did not focus specifically on ADT-related osteoporosis. Given this treatment goal [50], the 25(OH)D assay should be repeated once to adjust the initial and maintenance supplementation dosages in patients started on osteoporosis medication and in those at risk for falls (Professional consensus).

In patients with vitamin D insufficiency or deficiency, a loading dose of vitamin D should be given to increase the $25(\mathrm{OH}) \mathrm{D}$ level above the target value of $30 \mathrm{ng} / \mathrm{mL}$ ( Grade A). The suggested dosage scheme is as follows [50]: vitamin D deficiency $(25(\mathrm{OH}) \mathrm{D}<10$ $\mathrm{ng} / \mathrm{mL}$ ), four doses of $100000 \mathrm{IU}$ of cholecalciferol (vitamin D3) at 2-week intervals; vitamin D insufficiency (25(OH)D between 10 and $20 \mathrm{ng} / \mathrm{mL}), 3$ doses of $100000 \mathrm{IU}$ of cholecalciferol at 2-week intervals; and vitamin D insufficiency $(25(\mathrm{OH}) \mathrm{D}$ between 20 and $30 \mathrm{ng} / \mathrm{mL}$ ), two doses of $100000 \mathrm{IU}$ of cholecalciferol 2 weeks apart. Cholecalciferol in vials of 80000 IU each can also be used. 
For maintenance vitamin D supplementation, the usual cholecalciferol dosage is 800 to 1200 IU/day (or the equivalent dosage of 100000 IU every 2 or 3 months) but should be tailored to each individual patient. Currently available knowledge does not support the use of high doses of 500000 or 600000 IU once or twice a year [50] (Grade A). Dihydroxylated vitamin D derivatives are not recommended, in particular due to the risk of an increase in urinary calcium excretion ( $\underline{\text { Grade A) }}$. The maintenance vitamin D supplement dosage also varies with the BMI.

Studies suggest that vitamin D supplementation may be useful in preventing bone loss due to LHRH analog therapy [20]. Furthermore, appropriate calcium and vitamin supplementation must be started before the initiation of osteoporosis medications.

We recommend an annual 25(OH)D assay (Professional consensus). One study has suggested that high vitamin D levels may increase the progression of prostate cancer [51]. Although no such effect was found in earlier studies [52, 53, 54], caution mandates that vitamin D overdosage be avoided.

\section{Anti-osteoporosis treatment strategies}

An individually tailored strategy is suggested for preventing ADT-related bone loss and fractures. Although bisphosphonates have been proven effective in preventing bone loss [55-66], only toremifene [67] and denosumab [68] have been demonstrated to prevent bone loss and decrease the fracture risk in men receiving ADT (Table 3). However, most of the studies of bisphosphonates were not sufficiently powered to detect a fracture-reduction effect. 
A randomized placebo-controlled trial has evaluated the effect of denosumab in decreasing the risk of vertebral fractures in men given ADT to treat nonmetastatic prostate cancer [68]. Denosumab was administered subcutaneously in a dosage of $60 \mathrm{mg}$ every 6 months. Denosumab decreased the risk of vertebral fractures as assessed after 36 months. No evidence exists that denosumab [68] or toremifene [67] diminish the risk of nonvertebral fractures.

\subsection{Indications of osteoporosis therapy}

In males, several situations associated with a high fracture risk warrant the administration of osteoporosis medications (Figure 1):

- history of low-energy severe fracture after 50 years of age (Grade A). Fractures are severe if they involve the hip, proximal humerus, distal femur, pelvis, proximal tibia, three adjacent ribs, or one or more vertebras

- $\mathrm{T}$-score $\leq-2.5$ at one of the two measurement sites, i.e., the spine or femur (femoral neck or total hip) ( $\underline{\text { Grade A) }}$

- high risk of fracture based on a T-score $\leq-1.5$ and $>-2.5$ at the spine or hip PLUS at least two of the following risk factors: age $\geq 75$ years, history of nonsevere fracture after 50 years of age, BMI $<19 \mathrm{~kg} / \mathrm{m}^{2}$, at least three comorbidities (e.g., cardiovascular disease, depression, Parkinson's disease, and dementia), current glucocorticoid therapy, and repeated falls. Determining the FRAX ${ }^{\circledR}$ score may be helpful in difficult cases, the cutoff for osteoporosis treatment being $20 \%$ for major fractures and/or 3\% for hip fractures [16] (Professional consensus). The hypogonadism induced by ADT is among the causes of secondary osteoporosis. Evaluation by a bone diseases specialist is recommended in this situation. 
If osteoporosis treatment with a bisphosphonate or denosumab is not indicated, the general measures should be applied and the BMD measurements repeated 12 to 24 months after the first evaluation or after an interval deemed appropriate based on the initial BMD values (Professional consensus).

\subsection{Selecting the osteoporosis medication}

Bisphosphonates, denosumab, and toremifene have been proven to increase BMD values (Table 3). Toremifene was evaluated in a Phase III trial [67] but is not licensed for use in this indication in France, notably due to an increase in the risk of thromboembolic events. Denosumab is the only medication licensed for use and proven to decrease the risk of vertebral fractures in this indication [68] (Grade A). Denosumab is not reimbursed in France. Pamidronate was evaluated in a therapeutic trial, in a dosage of $60 \mathrm{mg}$ every 3 months [55]. However, pamidronate is not recommended in this indication (Professional consensus). Neridronate is not commercially available in France.

In every case, the following bisphosphonates can be used: zoledronic acid, alendronate, and risedronate (Grade B) $[58,59,60,61,62,63,64,65,66]$. Among oral bisphosphonates, alendronate $[62,63,64]$ and risedronate $[65,66]$ were evaluated in this indication in dosages of $70 \mathrm{mg} /$ week and $35 \mathrm{mg} / \mathrm{week}$, respectively. Studies of zoledronic acid used $4 \mathrm{mg}$ every 3 months [58, 59, 61] and every 12 months [60]. The dosage of $5 \mathrm{mg}$ every 12 months is recommended in this indication (Professional consensus). It is also the standard recommended dosage in patients at high risk for osteoporotic fractures.

Oral or intravenous bisphosphonate therapy should be used as the first-line osteoporosis medication. In patients with contraindications or intolerance to bisphosphonates, the use of denosumab should be considered (Professional consensus). 


\subsection{Duration of use and conditions of discontinuation of osteoporosis therapy}

The available therapeutic trials lasted only 6 to 36 months and cannot therefore serve to determine the optimal treatment duration. Clinical experience with osteoporosis medications in men on ADT is 2 years for bisphosphonates and 36 months for denosumab.

An initial treatment duration of 3 to 5 years is recommended, with a reevaluation at the end of this first period (Professional consensus). The reevaluation does not necessarily lead to treatment discontinuation. Treatment discontinuation after the first period can be recommended in patients meeting the following criteria: no bone loss AND no incident nontraumatic fracture AND T-score >-2.5 at the hip AND discontinuation of the ADT (Professional consensus). In every case, the decision to discontinue osteoporosis therapy rests on an evaluation of the risk/benefit ratio in the individual patient.

\section{Patient follow-up}

\subsection{Evaluation of treatment adherence}

Treatments of osteoporosis, similar to all treatments for chronic diseases, work only if taken as prescribed. In several studies, poor adherence to osteoporosis therapy was associated with decreased efficacy. Clinical follow-up can be sufficient to assess treatment adherence (Professional consensus). 


\subsection{Role for bone mineral density (BMD) measurements during follow-up}

Given the rapid pace of bone loss during ADT, BMD values should be measured 12 to 24 months after the baseline evaluation in the absence of osteoporosis therapy, depending on the initial BMD values (Professional consensus). If osteoporosis therapy is initiated, BMD measurement is recommended after the first 3- to 5-year treatment period.

\subsection{Role for bone turnover marker assays}

No evidence exists that bone turnover marker assays are useful for monitoring osteoporosis therapy in patients with ADT-related osteoporosis.

\subsection{Other follow-up criteria}

Height should be measured once a year, as vertebral fractures result in height loss. Height loss is a nonspecific sign of spinal disease that may warrant an imaging study of the spine (radiography or VFA) (Professional consensus). A morphological evaluation of the spine is indicated in patients with back pain or height loss $\geq 2 \mathrm{~cm}$ during follow-up.

\section{Treatment safety}

Clinical trials in patients with osteoporosis induced by LHRH agonist therapy included fewer patients and had shorter durations than those conducted in postmenopausal osteoporosis and male osteoporosis. Few data are available from patients given prolonged ADT. The safety profiles of bisphosphonates and denosumab seem comparable to those seen 
in postmenopausal and male osteoporosis. Importantly, no cases of osteonecrosis of the jaw or atypical femoral fracture were recorded during clinical trials of bisphosphonates or denosumab used to prevent bone loss in patients with prostate cancer $[55,56,57,58,59,60$, $61,62,63,64,65,66,68]$. Nevertheless, the patients should be informed of the very low risk of osteonecrosis of the jaw and atypical femoral fracture. Oral health should be evaluated at baseline then once a year.

\section{Disclosure of interest}

KB: honoraria for work as an expert or speaker for Amgen, Lilly, Kyowa Kirin International, and MSD

JP: no conflicts of interest related to this article

PB: honoraria for work as an expert or speaker for Amgen, Novartis, Bayer, Sanofi, Astellas, Janssen, and Roche

JB: no conflicts of interest related to this article

BB: no conflicts of interest related to this article

CBC: honoraria for work as an expert or speaker for Lilly, Amgen, and Expanscience

CC: no conflicts of interest related to this article

BC: honoraria for work as an expert or speaker for Amgen, Expanscience, Ferring, Lilly, MSD, Medtronic, Meda, and Roche Diagnostics; financial support for research programs from Amgen, Novartis, and Servier

JM HL: no conflicts of interest related to this article

$\mathrm{CH}$ : honoraria for work as an expert or speaker for Amgen, Ipsen, Astellas, Janssen, Roche, Sanofi

RMJ: no conflicts of interest related to this article 
EL: honoraria for work as an expert or speaker for Amgen, Expanscience, Lilly, and MSD; and financial support for research programs from, or investigator for Abbvie, Amgen, Lilly, MSD, and UCB

DM: honoraria for work as an expert or speaker for Amgen Archimedes, Janssen-Cilag , LEO Pharma, Novartis, Pfizer, Roche, Sandoz, Sanofi, and Vifor PMA: honoraria for work as an expert or speaker for Amgen, Ferring, Janssen, Astellas, Ipsen, and Sanofi

MHV: honoraria for work as an expert or speaker for Amgen, Keocyt, and Bioprojet FD: honoraria for work as an expert or speaker for Abbot, Alexion, Amgen, Lilly, MSD, Roche, Novartis, and Servier

We thank the members of the revision panel: Jean-Jaques Body (Internal Medicine, Brussels, Belgium), Mario di Palma (Medical Oncology, Gustave Roussy Institute, Villejuif, France) Fadila Farsi (Oncology, Lyon, France), Pascal Guggenbuhl (Rheumatology, Rennes, France), Jean-Léon Lagrange (Radiotherapy, Créteil, France), Erick Legrand (Rheumatology, Angers, France), Christian Marcelli (Rheumatology, Caen, France), François Rozet (Urological Surgery, Institut Montsouris, Paris, France), Laurence Vanlemmens (Oncology, Lille, France) 


\section{References}

[1] Les cancers en France/Edition 2016. Institut National du Cancer. www.e-cancer.fr

[2] D'Amico AV, Whittington R, Malkowicz SB et al. Biochemical outcome after radical prostatectomy, external beam radiation therapy, or interstitial radiation therapy for clinically localized prostate cancer. JAMA 1998;280:969-74.

[3] Guide - Affection de longue durée. Cancer de la prostate. HAS/INCa Janvier 2012

[4] D'Amico AV, et al. 6-month androgen suppression plus radiation therapy versus

radiation therapy alone for patients with clinically localized prostate cancer: a randomized controlled trial. JAMA 2004;292:821-7.

[5] Zapatero A et al. High-dose radiotherapy with short-term or long-term androgen deprivation in localised prostate cancer (DART01/05 GICOR): a randomised, controlled, phase 3 trial. Lancet Oncol. 2015;16:320-7

[6] Bolla $\mathrm{M}$ et al. External irradiation with or without long-term androgen suppression for prostate cancer with high metastatic risk: 10-year results of an EORTC randomised study. Lancet Oncol. 2010;11:1066-73.

[7] Bolla $\mathrm{M}$ et al. Duration of androgen suppression in the treatment of prostate cancer. $\mathrm{N}$ Engl J Med 2009;360:2516-27.

[8] Crook $\mathbf{J}$ et al. Intermittent androgen suppression for rising PSA level after radiotherapy. N Engl J Med 2012;367:895-903.

[9] Hussain et al., Intermittent versus continuous androgen deprivation in prostate cancer. $\mathrm{N}$ Engl J Med, 2013, 368 : 1314-1325

[10] de Bono JS, et al. Abiraterone and increased survival in metastatic prostate cancer. N Engl J Med. 2011;364:1995-2005. 
[11] Beer TM et al. Enzalutamide in metastatic prostate cancer before chemotherapy. N Engl J Med 2014; 371: 424-33

[12] Tannock IF, et al. Docetaxel plus prednisone or mitoxantrone plus prednisone for advanced prostate cancer. N Engl J Med. 2004;351:1502-12.

[13] de Bono JS, et al. Prednisone plus cabazitaxel or mitoxantrone for metastatic castrationresistant prostate cancer progressing after docetaxel treatment: a randomised open-label trial. Lancet. 2010;376:1147-54.

[14] Parker C et al. Alpha emitter radium-223 and survival in metastatic prostate cancer. N Engl J Med 2013;369:213-23.

[15] Rozet F, Hennequin C, Beauval JB, et al. CCAFU French national guidelines 20162018 on prostate cancer. Prog Urol. 2016 Nov;27 Suppl 1:S95-S143.

[16] Rizzoli R, Body JJ, Brandi ML et al. Cancer-associated bone disease. Osteoporos Int $2013 ; 24: 2929-53$.

[17] Gralow JR, Biermann JS, Farooki A et al. NCCN Task Force report: Bone health in cancer care. J Natl Compr Canc Netw 2013 ;11 Suppl 3:S1-50.

[18] Berruti A, Dogliotti L, Terrone C, et al., Gruppo Onco Urologico Piemontese (G.O.U.P.), Rete Oncologica Piemontese. Changes in bone mineral density, lean body mass and fat content as measured by dual energy x-ray absorptiometry in patients with prostate cancer without apparent bone metastases given androgen deprivation therapy. J Urol. 2002 ; $167: 2361-7$.

[19] Morote J, Morin JP, Orsola A,et al. Prevalence of osteoporosis during long-term androgen deprivation therapy in patients with prostate cancer. Urology 2007;69:500-504 . [20] Alibhai SM, Mohamedali HZ, Gulamhusein H, et al. Changes in bone mineral density in men starting androgen deprivation therapy and the protective role of vitamin D. Osteoporos Int. 2013; $24: 2571-9$. 
[21] Maillefert JF, Sibilia J, Michel F et al. Bone mineral density in men treated with synthetic gonadotropin-releasing hormone agonists for prostatic carcinoma. J Urol $1999 ; 161: 1219-22$

[22] Higano C, Shields A, Wood N, et al. Bone mineral density in patients with prostate cancer without bone metastases treated with intermittent androgen suppression. Urology. $2004 ; 64$ : 1182-6.

[23] Morote, Orsola A, Abascal J et al. Bone mineral density changes in prostate cancer patients during the first two years of androgen suppression. J Urol 2006;175:1679-83 [24] Daniell HW, Dunn SR, Ferguson DW, et al. Progressive osteoporosis during androgen deprivation therapy for prostate cancer. J Urol. 2000 ; 163 : 181-6.

[25] Mittan D, Lee S, Miller E, et al. Bone loss following hypogonadism in men with prostate cancer treated with GnRH analogs. J Clin Endocrinol Metab 2002; 87: 3656-61. [26] Preston DM, Torréns JI, Harding P, et al. Androgen deprivation in men with prostate cancer is associated with an increased rate of bone loss. Prostate Cancer Prostatic Dis. $2002 ; 5: 304-10$.

[27] Ahlborg HG, Nguyen ND, Center JR, et al. Incidence and risk factors for low trauma fractures in men with prostate cancer. Bone 2008; 43 : 556-60.

[28] Spry NA, Galvão DA, Davies R, et al. Long-term effects of intermittent androgen suppression on testosterone recovery and bone mineral density: results of a 33-month observational study. BJU Int. $2009 ; 104$ : 806-12.

[29] Yu EY, Kuo KF, Gulati R, et al. Long-term dynamics of bone mineral density during intermittent androgen deprivation for men with nonmetastatic, hormone-sensitive prostate cancer. J Clin Oncol. $2012 ; 30$ : 1864-70. 
[30] Conde FA, Sarna L, Oka RK, et al. Age, body mass index, and serum prostate-specific antigen correlate with bone loss in men with prostate cancer not receiving androgen deprivation therapy. Urology. 2004;64: 335-40.

[31] Smith MR, Lee WC, Brandman J, et al. Gonadotropin-releasing hormone agonists and fracture risk: a claims-based cohort study of men with nonmetastatic prostate cancer. J Clin Oncol. 2005 ; 23: 7897-903

[32] Shahinian VB, Kuo YF, Freeman JL, et al. Risk of fracture after androgen deprivation for prostate cancer. N Engl J Med 2005;352:154-164

[33] Abrahamsen B, Nielsen MF, Eskildsen P, et al. Fracture risk in Danish men with prostate cancer: a nationwide register study. BJU Int. 2007;100 : 749-54.

[34] Shao YH, Moore DF, Shih W, et al. Fracture after androgen deprivation therapy among men with a high baseline risk of skeletal complications. BJU Int. $2013 ; 111$ : 745-52.

[35] Bliuc D, Nguyen ND, Milch VE, et al. Mortality risk associated with low-trauma osteoporotic fracture and subsequent fracture in men and women. JAMA. 2009 ; 301 : 513 21

[36] Greenspan SL, Wagner J, Nelson JB, et al. Vertebral fractures and trabecular microstructure in men with prostate cancer on androgen deprivation therapy. J Bone Miner Res $2013 ; 28: 325-32$

[37] Angeli A, Guglielmi G, Dovio A, et al. High prevalence of asymptomatic vertebral fractures in post-menopausal women receiving chronic glucocorticoid therapy: a cross-sectional outpatient study. Bone. 2006 ; 39 : 253-9.

[38] Alibhai SM, Duong-Hua M, Cheung AM, et al. Fracture types and risk factors in men with prostate cancer on androgen deprivation therapy: a matched cohort study of 19,079 men. J Urol. $2010 ; 184: 918-23$. 
[39] Saylor PJ, Morton RA, Hancock ML, et al. Factors associated with vertebral fractures in men treated with androgen deprivation therapy for prostate cancer. J Urol. 2011;186 : 482-6. [40] Lau YK, Lee E, Prior HJ, et al. Fracture risk in androgen deprivation therapy: a Canadian population based analysis. Can J Urol. $2009 ; 16$ : 4908-14.

[41] Dargent-Molina P, Favier F, Grandjean H, et al. Fall-related factors and risk of hip fracture: the EPIDOS prospective study. Lancet. 1996;348:145-9.

[42] Bylow K, Hemmerich J, Mohile SG, et al. Obese frailty, physical performance deficits, and falls in older men with biochemical recurrence of prostate cancer on androgen deprivation therapy: a case-control study. Urology. 2011; 77 : 934-40.

[43] Shepherd JA, Schousboe JT, Broy SB, et al. Executive Summary of the 2015 ISCD Position Development Conference on Advanced Measures From DXA and QCT: Fracture prediction beyond BMD. J Clin Densitom. 2015 ; 18 : 274-86.

[44] Soubeyran P, Bellera C, Goyard J et al. Screening for vulnerability in older cancer patients: the ONCODAGE prospective multicenter cohort study. PLoS One 2014 ; 9 : e115060.

[45] Binkley NC, Schmeer P, Wasnich RD, et al. What are the criteria by which a densitometric diagnosis of osteoporosis can be made in males and non-Caucasians? J Clin Densitom 2002;5:219-27.

[46] Faulkner KG, Orwoll E. Implications in the use of T scores for the diagnosis of osteoporosis in men. J Clin Densitom 2002;5:S19-27.

[47] Leslie WD, Adler RA, El-Hajj Fuleihan G, et al. Application of the 1994 WHO classification to populations other than postmenopausal Caucasian women: the 2005 ISCD official positions. J Clin Densitom 2006;9:22-30.

[48] Briot K, Cortet B, Trémollières F, et al. Comité Scientifique du GRIO. Male osteoporosis: diagnosis and fracture risk evaluation. Joint Bone Spine. 2009;76:129-33. 
[49] Kanis JA, Johnell O, Oden A, et al. FRAX and the assessment of fracture probability in men and women from the UK. Osteoporos Int. 2008;19:385-97.

[50] Benhamou CL, Souberbielle JC, Cortet B, et al. La vitamine D chez l'adulte : recommandations du GRIO. Presse Med 2011;40:673-8.

[51] Xu Y, Shao X, Yao Y, Xu L, et al. Positive association between circulating 25hydroxyvitamin D levels and prostate cancer risk: new findings from an updated metaanalysis. J Cancer Res Clin Oncol 2014;140:1465-77.

[52] Yin L, Raum E, Haug U, et al. Meta-analysis of longitudinal studies: serum vitamin D and prostate cancer risk. Cancer Epidemiol. 2009;33:435-445.

[53] Gandini S, Boniol M, Haukka J, et al. Meta-analysis of observational studies of serum 25-hydroxyvitamin D levels and colorectal, breast and prostate cancer and colorectal adenoma. Int. J. Cancer. 2011;128:1414-1424.

[54] Gilbert R, Martin RM, Beynon R, et al. Associations of circulating and dietary vitamin $\mathrm{D}$ with prostate cancer risk: a systematic review and dose-response meta-analysis. Cancer Causes Control. 2011;22:319-340.

[55] Smith MR, McGovern FJ, Zietman AL, et al. Pamidronate to prevent bone loss during androgen-deprivation therapy for prostate cancer. N Engl J Med. 2001;345:948-55.

[56] Morabito N, Gaudio A, Lasco A, et al. Neridronate prevents bone loss in patients receiving androgen deprivation therapy for prostate cancer. J Bone Miner Res. 2004 ; 19 : 1766-70.

[57] Magno C, Anastasi G, Morabito N, et al. Preventing bone loss during androgen deprivation therapy for prostate cancer: early experience with neridronate. Eur Urol. 2005 ; 47: $575-80$ 
[58] Smith MR, Eastham J, Gleason DM, et al. Randomized controlled trial of zoledronic acid to prevent bone loss in men receiving androgen deprivation therapy for non-metastatic prostate cancer. J Urol. 2003;169:2008-12.

[59] Ryan CW, Huo D, Demers LM, et al. Zoledronic acid initiated during the first year of androgen deprivation therapy increases bone mineral density in patients with prostate cancer. J Urol. 2006;176:972-8.

[60] Michaelson MD, Kaufman DS, Lee H, et al. Randomized controlled trial of annual zoledronic acid to prevent gonadotropin-releasing hormone agonist-induced bone loss in men with prostate cancer. J Clin Oncol. 2007;25:1038-42.

[61] Bhoopalam N, Campbell SC, Moritz T, et al. Intravenous zoledronic acid to prevent osteoporosis in a veteran population with multiple risk factors for bone loss on androgen deprivation therapy. J Urol 2009;182:2257-2264.

[62] Greenspan SL, Nelson JB, Trump DL, et al. Effect of once-weekly oral alendronate on bone loss in men receiving androgen deprivation therapy for prostate cancer. Ann Intern Med. 2007;146:416-24.

[63] Planas J, Trilla E, Raventós C, et al. Alendronate decreases the fracture risk in patients with prostate cancer on androgen-deprivation therapy and with severe osteopenia or osteoporosis. BJU Int. 2009;104:1637-40 [64] Klotz LH, McNeill IY, Kebabdjian M, et al. A phase 3, double-blind, randomised, parallel-group, placebo-controlled study of oral weekly alendronate for the prevention of androgen deprivation bone loss in nonmetastatic prostate cancer: the Cancer and Osteoporosis Research with Alendronate and Leuprolide (CORAL) study. Eur Urol 2012;63:927-935. 
[65] Taxel P, Dowsett R, Richter L, Fall P, et al. Risedronate prevents early bone loss and increased bone turnover in the first 6 months of luteinizing hormone-releasing hormoneagonist therapy for prostate cancer. BJU Int 2010;106:1473-1476.

[66] Choo R, Lukka H, Cheung P, et al. Randomized, double-blinded, placebo-controlled, trial of risedronate for the prevention of bone mineral density loss in nonmetastatic prostate cancer patients receiving radiation therapy plus androgen deprivation therapy. Int J Radiat Oncol Biol Phys. 2013;85: 1239-45.

[67] Smith MR, Morton RA, Barnette KG, et al. Toremifene to reduce fracture risk in men receiving androgen deprivation therapy for prostate cancer. J Urol. 2010;184:1316-21. [68] Smith MR, Egerdie B, Hernandez Toriz N, et al. Denosumab in men receiving androgen-deprivation therapy for prostate cancer. N Engl J Med. 2009;361(8):745-75 
Figure 1

French recommendations for preventing bone loss due to androgen-deprivation therapy (ADT) for prostate cancer 


\section{Prevention of bone loss due to ADT for prostate cancer}

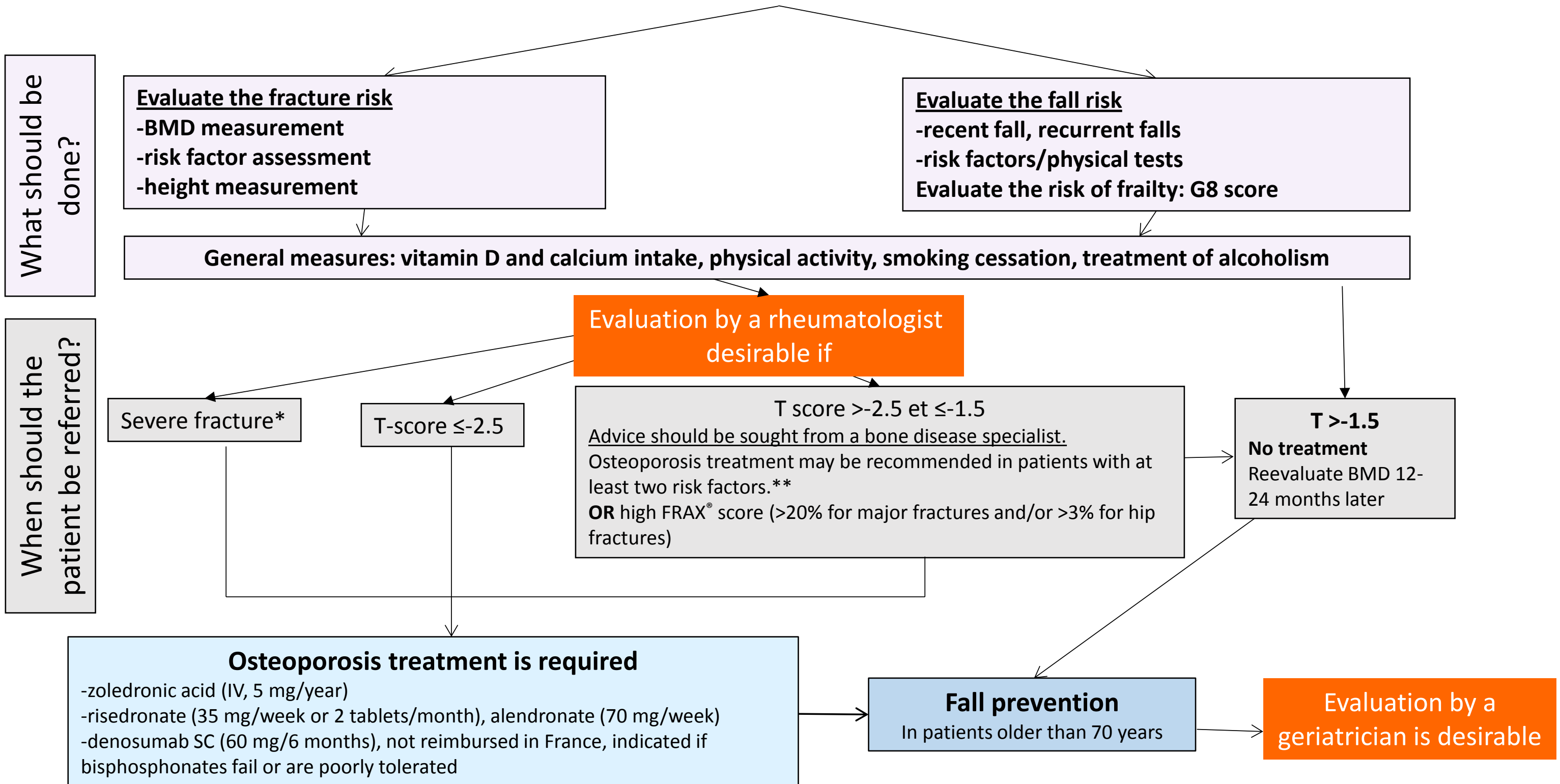

bisphosphonates fail or are poorly tolerated

*fractures of the hip, proximal humerus, distal femur, pelvis, proximal tibia, three consecutive ribs, and one or more vertebras

*age $\geq 75$ years, high risk of falls (recurrent falls), history of nonsevere low-energy fracture after 50 years of age, BMI $<19 \mathrm{~kg} / \mathrm{m}^{2}$, at least three comorbidities (e.g., cardiovascular disease, depression, Parkinson's disease, dementia), and current glucocorticoid therapy 
Table 1: D'Amico risk classification of biochemical recurrence 10 years after local treatment for localized prostate cancer (from [2] and [3])

\begin{tabular}{|l|c|c|c|}
\hline & Low risk & Intermediate risk & High risk \\
\hline Clinical stage & $\leq \mathrm{T} 2 \mathrm{a}$ & $\mathrm{T} 2 \mathrm{~b}$ & $\mathrm{~T} 2 \mathrm{c}-\mathrm{T} 3 \mathrm{a}$ \\
\hline Gleason score & and $\leq 6$ & or 7 & or $\geq 8$ \\
\hline $\begin{array}{l}\text { Serum PSA } \\
(\mathbf{n g} / \mathbf{m L})\end{array}$ & and $\leq 10$ & or $10<\mathrm{PSA} \leq 20$ & or $>20$ \\
\hline
\end{tabular}

PSA, prostate-specific antigen 
Table 2: Hormone treatments used in prostate cancer

\begin{tabular}{|c|c|c|}
\hline \multirow[t]{4}{*}{ LHRH analogs } & Goserelin & Zoladex ${ }^{\circledR}$ \\
\hline & Buserelin & Bigonist ${ }^{\circledR}$, Suprefact ${ }^{\circledR}$ \\
\hline & Leuprorelin & Enantone LP®, Eligard® \\
\hline & Triptorelin & Decapeptyl®, Gonapeptyl® \\
\hline LHRH antagonists & Degarelix & Firmagon ${ }^{\circledR}$ \\
\hline \multirow{2}{*}{$\begin{array}{l}\text { Peripheral steroid } \\
\text { antiandrogens }\end{array}$} & Bicalutamide & Casodex $®$ \\
\hline & Flutamide & Eulexine ${ }^{\circledR}$ \\
\hline \multirow{2}{*}{$\begin{array}{l}\text { Peripheral } \\
\text { nonsteroid } \\
\text { antiandrogens }\end{array}$} & Cyproterone acetate & Androcur ${ }^{\circledR}$ \\
\hline & Nilutamide & Anandron $®$ \\
\hline
\end{tabular}


Table 3: Main randomized placebo-controlled trials evaluating the effects of osteoporosis medications on bone mineral density values in patients with prostate cancer and LHRH analog-induced osteoporosis

\begin{tabular}{|c|c|c|c|c|c|c|c|}
\hline \multirow{3}{*}{$\begin{array}{l}\text { Treatments } \\
\text { [reference] } \\
\text { dosage }\end{array}$} & \multirow{3}{*}{$\begin{array}{c}\text { Number of } \\
\text { patients (n) } \\
\text { Treatment } \\
\text { duration }\end{array}$} & \multicolumn{6}{|c|}{ BMD changes $(\%)$} \\
\hline & & \multicolumn{3}{|c|}{ Lumbar spine } & \multicolumn{3}{|c|}{ Total hip } \\
\hline & & Verum & $\mathrm{PBO}$ & $\begin{array}{c}P \\
\text { value }\end{array}$ & Verum & PBO & $P$ value \\
\hline $\begin{array}{l}\text { Pamidronate [53] } \\
60 \mathrm{mg} / 3 \text { months }\end{array}$ & $\begin{array}{l}\mathrm{n}=47 \\
(12 \text { months })\end{array}$ & - & -3.3 & $<0.001$ & - & -1.8 & 0.005 \\
\hline $\begin{array}{l}\text { Neridronate [54] } \\
25 \mathrm{mg} / \mathrm{month} \mathrm{IM}\end{array}$ & $\begin{array}{l}\mathrm{n}=48 \\
(12 \text { months })\end{array}$ & - & -4.9 & $<0.05$ & - & -1.9 & $<0.05$ \\
\hline $\begin{array}{l}\text { Neridronate [55] } \\
25 \mathrm{mg} / \mathrm{month} \mathrm{IM}\end{array}$ & $\begin{array}{l}\mathrm{n}=60 \\
(12 \text { months })\end{array}$ & +1.0 & -4.9 & - & +0.8 & -1.9 & - \\
\hline $\begin{array}{l}\text { Zoledronic acid [56] } \\
4 \mathrm{mg} / 3 \text { months }\end{array}$ & $\begin{array}{l}\mathrm{n}=106 \\
(12 \text { months })\end{array}$ & +5.6 & -2.2 & $<0.001$ & +1.1 & -2.8 & $<0.001$ \\
\hline $\begin{array}{l}\text { Zoledronic acid } \\
\text { [57] } \\
4 \mathrm{mg} / 3 \text { months }\end{array}$ & $\begin{array}{l}\mathrm{n}=120 \\
(12 \text { months })\end{array}$ & +4.6 & -2.1 & $<0.001$ & +1.4 & -2.4 & $<0.001$ \\
\hline $\begin{array}{l}\text { Zoledronic acid } \\
\text { [58] } \\
4 \mathrm{mg} / 12 \text { months }\end{array}$ & $\begin{array}{l}\mathrm{n}=40 \\
(12 \text { months })\end{array}$ & +4.0 & -3.1 & $<0.001$ & +0.7 & -1.9 & 0.004 \\
\hline $\begin{array}{l}\text { Zoledronic acid } \\
\text { [59] } \\
4 \mathrm{mg} / 3 \text { months }\end{array}$ & $\begin{array}{l}\mathrm{n}=93 \\
\text { (12 months) }\end{array}$ & +5.1 & -3.1 & 0.004 & - & - & - \\
\hline $\begin{array}{l}\text { Alendronate [60] } \\
70 \mathrm{mg} / \text { week }\end{array}$ & $\begin{array}{l}\mathrm{n}=112 \\
(12 \text { months })\end{array}$ & +3.7 & $-1.4 \%$ & $<0.001$ & $+1.6^{*}$ & $-0.7 *$ & $<0.001$ \\
\hline $\begin{array}{l}\text { Alendronate [61] } \\
70 \mathrm{mg} / \text { week }\end{array}$ & $\begin{array}{l}\mathrm{n}=61 \\
\text { (12 months) }\end{array}$ & - & - & 0.001 & - & - & 0.001 \\
\hline $\begin{array}{l}\text { Alendronate [62] } \\
70 \mathrm{mg} / \text { week }\end{array}$ & $\begin{array}{l}\mathrm{n}=191 \\
\text { (12 months) }\end{array}$ & +1.7 & -1.9 & $<0.001$ & +0.7 & -1.6 & 0.63 \\
\hline $\begin{array}{l}\text { Risedronate [63] } \\
35 \mathrm{mg} / \text { week }\end{array}$ & $\begin{array}{l}\mathrm{n}=40 \\
(6 \text { months })\end{array}$ & +1.7 & -1.2 & - & +0.3 & -2.2 & - \\
\hline $\begin{array}{l}\text { Risedronate [64] } \\
35 \mathrm{mg} / \text { week }\end{array}$ & $\begin{array}{l}\mathrm{n}=104 \\
(24 \text { months })\end{array}$ & +0.8 & -13.5 & - & - & - & - \\
\hline $\begin{array}{l}\text { Toremifene [65] } \\
80 \mathrm{mg} / \text { day }\end{array}$ & $\begin{array}{l}\mathrm{n}=1284 \\
(24 \text { months })\end{array}$ & - & - & $<0.001$ & - & - & $<0.001$ \\
\hline $\begin{array}{l}\text { Denosumab [66] } \\
60 \mathrm{mg} / 6 \text { months }\end{array}$ & $\begin{array}{l}\mathrm{n}=1468 \\
(24 \text { months })\end{array}$ & +5.6 & -1.0 & $<0.001$ & +2.8 & -2.0 & $<0.001$ \\
\hline
\end{tabular}

BMD, bone mineral density; PBO, placebo; IM, intramuscularly;

*BMD change at the femoral neck and not at the total hip 